\title{
El devenir de la situación laboral docente en el proceso de transferencia del servicio educativo nacional de nivel primario durante la última dictadura argentina. 1976-1981
}

\author{
Mariana Gudelevicius \\ (Universidad de Buenos Aires. \\ CONICET. Argentina)
}

\section{Resumen}

Entre 1976 y 1983 la Argentina vivió una dictadura efectuada por las Fuerzas Armadas y grupos civiles afines siendo el principal, el sector empresarial vinculado a José Alfredo Martínez de Hoz.

Uno de los pilares de la política educativa dictatorial fue la descentralización de la educación y la administración escolar. A través de la política de transferencias se descargó en las provincias el sostenimiento del servicio educativo primario, agravando los problemas estructurales que este presentaba y favoreciendo a la educación privada. El contexto de terrorismo de estado posibilitó la concreción de las medidas al limitar la capacidad de oposición social. Sin embargo, el proceso no estuvo exento de conflictos y denuncias.

El propósito de este artículo es analizar el proceso de transferencia de escuelas nacionales de nivel primario a las jurisdicciones provinciales, la Municipalidad de la Ciudad de Buenos Aires y el Territorio Nacional de Tierra del Fuego efectuado durante la última dictadura argentina, observando el devenir de la situación laboral docente en dicho proceso.

El estudio concluye que las transferencias no fueron articuladas con medidas que acompañaran a las regiones en la resolución de problemas como la deserción escolar y el deterioro de las condiciones laborales docentes. Por el contrario, los resultados fuero el cierre de escuelas, la superpoblación de aulas, la pérdida de puestos de trabajo y la renuncia masiva de docentes.

Palabras clave:

Dictadura - Política Educativa - Descentralización - Transferencias - Docentes. 


\section{Summary}

Between 1976 and 1983 Argentina lived a dictatorship conducted by the Armed Forces and compatible civil groups being the main one, the tie enterprise sector to Jose Alfredo Martinez de Hoz.

One of the pillars of the dictatorial educative policy was the decentralization of the education and the scholastic administration. Through the policy of transferences the support of primary the educative service unloaded in the provinces, aggravating the structural problems that this presented, displayed and favoring to the private education. The context of state terrorism made possible the concretion of the measures when limiting the capacity of social opposition. Nevertheless, the process was not free of conflicts and denunciations.

The intention of this article is to analyze the process of transference of national schools of primary level to the provincial jurisdictions, the Municipality of the City of Buenos Aires and the National Territory of Tierra Del Fuego carried out during the last Argentine dictatorship, observing happening of the elementary teacher labor situation in this process. The study concludes that the transferences were not articulated with measures that accompanied to the regions in the resolution by problems like the scholar desertion and the deterioration by the elementary teacher labor conditions. On the contrary, the results law the closing of schools, the overpopulation of classrooms, the loss of jobs and the massive resignation of elementary teachers.

\section{Key words}

Dictatorship - Educative Policy - Decentralization - Transference - Elementary Teachers.

\section{Introducción}

El 24 de marzo de 1976 la Junta de Comandantes en Jefe de la Argentina usurpó el gobierno constitucional por medio de un golpe de Estado con el apoyo de diversos grupos civiles, siendo el principal el sector empresarial vinculado a José Alfredo Martínez de Hoz.

En el marco de una crisis del modelo económico implementado en 1955 y con el trasfondo de grandes modificaciones en el orden internacional y de fuerte conflictividad social en el orden interno, el bloque social que ejecutó el golpe de estado impulsó un proyecto regresivo (subsidiariedad del estado, privatizaciones, apertura económica y liberalización del mercado de capitales) que exigía, para imponerlo, una profunda reestructuración productiva y una fuerte represión social.

Así mismo, la aplicación de políticas neoliberales tendientes a la reducción del gasto público, la descentralización administrativa y la privatización de servicios sociales, produjo una paulatina transformación del rol del estado con consecuencias tanto para los sectores sociales más pobres como para 
los trabajadores estatales. En este marco, el autodenominado "Proceso de Reorganización Nacional" (PRN) propuso profundizar la tendencia de décadas anteriores de modernización del sistema educativo subordinándolo a las demandas del mercado y al modelo de distribución regresiva de la renta mediante el estímulo a la educación privada pero también con propuestas de arancelar la enseñanza estatal no obligatoria (1).

Uno de los pilares de la política educativa dictatorial fue retomar y profundizar la tendencia a la descentralización de la educación y la administración escolar que se venían ensayando en el país desde finales de la década del cincuenta. El contexto de terrorismo de estado posibilitó la concreción de las medidas al limitar la capacidad de oposición social.

El propósito de este artículo es analizar el proceso de transferencia de escuelas nacionales de nivel primario a las jurisdicciones provinciales, la Municipalidad de la Ciudad de Buenos Aires y el Territorio Nacional de la tierra del Fuego, Antártida e Islas del Atlántico Sur efectuado durante la última dictadura argentina, observando la situación laboral docente en dicho proceso.

En el primer apartado del artículo, presentamos una breve reseña de los cambios de política educativa en relación a la articulación Estado Nacional / Provincias del sistema educativo.

En el segundo apartado, analizamos el proceso general de transferencias efectuado durante el PRN.

En el tercer apartado, analizamos específicamente el caso de la Municipalidad de la Ciudad de Buenos Aires.

\section{Los cambios en la articulación educativa Nación / Provincias}

En este apartado presentamos una breve reseña de los cambios de política nacional en relación a la articulación educativa entre el Estado Nacional y las provincias. Abordaremos la relación entre estos actores sociales respecto a la provisión de educación primaria. El período estudiado comprende la constitución del sistema educativo nacional y las diferentes etapas de transformación del mismo. El recorrido incluye menciones a la situación laboral docente, particularmente la cuestión salarial y acciones de oposición.

La Constitución Nacional de 1953 establecía la obligación provincial de proveer educación primaria a los habitantes y otorgaba al Congreso Nacional la atribución de dictar los planes generales de educación (2). En 1884, con la sanción de la Ley 1420 de Educación Común, se estableció por primera vez un programa básico de educación nacional, basado en la obligatoriedad, gratuidad y el laicismo, para niños de 6 a 14 años. Por medio 
de esta ley, el Estado Nacional -a través de la creación del Consejo Nacional de Educación- comenzó a administrar directamente escuelas en la Capital Federal y los diez Territorios Nacionales que existían en ese momento.

A partir de 1890, el Estado Nacional empezó a subsidiar a los gobiernos provinciales para el pago de sueldos del personal educativo, la adquisición de equipamientos y material para las escuelas. En 1905, con la sanción de la Ley 4874 -conocida como Ley Lainez- el gobierno nacional quedaba facultado, por medio del Consejo Nacional de Educación (CNE) a crear escuelas elementales, infantiles, mixtas y rurales, en territorios provinciales, a solicitud de las provincias (para ajustarse a lo normado por la Constitución Nacional).

La ley Lainez, que había surgido como un instrumento de emergencia, pasó a tener carácter prácticamente definitivo. Desde ese momento, se configuró un circuito paralelo de escuelas provinciales y nacionales en un mismo territorio, con competencias encontradas y manifiestas repercusiones para los docentes (3). Esta situación generaba que, dentro del propio sistema educativo estatal -incluso en un mismo barrio-, coexistieran dos tipos de instituciones públicas con grandes diferencias en cuanto a edificación, programas de estudio, escalafón y salario docente, tipo de dependencia administrativa e incluso diferencias en torno a la valoración social diferenciada de la calidad educativa de uno u otro tipo de escuela (4). Antes de la sanción del Estatuto del Docente, la posibilidad de acceder a cargos ya sea en escuelas nacionales o en aquéllas con una ubicación geográfica favorable, provocaba que los maestros y las maestras fueran objeto de manipulación y clientelismo político (5).

Durante la administración del presidente Arturo Frondizi, comenzaron los primeros intentos por transferir las escuelas primarias nacionales a las provincias.

Si bien la propuesta de "Desarrollo e Integración" del frondizismo tuvo eco en vastos sectores de educadores, especialmente al concretar la sanción del Estatuto del Docente, muy pronto las medidas de política educativa del gobierno generaron una fuerte oposición del sector.

Uno de los principios más controvertidos de la propuesta educativa del frondizismo fue la instalación del paradigma tecnocrático por el cual se planteaba una alianza entre el Estado y el capital privado. A partir de la "recomendaciones" de la Comisión Económica para América Latina (CEPAL) se sugería a los gobiernos que: "incrementen sus esfuerzos para impulsar el mejoramiento cualitativo de la educación general y la formación profesional mediante planes integrales de educación estrechamente vinculados con los de desarrollo económico y social (...) y que tengan presente las 
necesidades de los próximos años en cuanto al número de profesionales y técnicos, tipo de especialización y nivel de los mismos" (6).

Entre las reformas del gobierno para cumplir las recomendaciones del organismo internacional, se promovió la autorización a la iniciativa privada para la creación de universidades libres que expidieran títulos y diplomas -hasta ese momento derecho reservado al Estado (7)- y se intentó la transferencia de escuelas primarias a la órbita provincial.

Esta etapa de transferencias tuvo como punto de partida una Ley de Presupuesto (8) en la que se daba la posibilidad de convenir con los gobiernos provinciales el traspaso de los servicios nacionales. Sólo se inscribieron inicialmente convenios con once provincias: Buenos Aires, Catamarca, Corrientes, Santa Fe, Chubut, Formosa, Neuquén, San Juan, San Luis, Santa Cruz y Santiago del Estero. Sin embargo, sólo tres de ellas -Neuquén, Santa Cruz y San Luis- ratificaron tales convenios. Ante la demora de la ratificación por parte de las restantes provincias, el Poder Ejecutivo Nacional, por decreto (9), y en forma unilateral en enero de 1962, dispuso realizar la transferencia de todos los establecimientos del CNE ubicados en territorios provinciales desde el comienzo del período lectivo de ese año que no se hubieran concretado hasta esa fecha. El saldo de ese período, que coincidió con la destitución del presidente Frondizi, fue el traspaso de 23 escuelas que funcionaban en la provincia de Santa Cruz. Finalmente, esta transferencia obligatoria fue dejada sin efecto durante el gobierno del Dr. José María Guido.

Por otra parte, entre los años 1958 y 1963 se produjeron en Buenos Aires varias protestas docentes por reclamos salariales y en defensa de la educación pública. Los docentes denunciaban retrasos en el cobro de haberes de hasta cuatro meses (10). En algunos casos, las protestas incluían el reclamo de equiparación de salarios de los maestros y profesores provinciales con los del orden nacional (11). Sin embargo, también ocurrió que, si la convocatoria partía de docentes de escuelas nacionales, los provinciales no adherían (12).

A fines de los años sesenta, nuevamente se instauró el tema de la política de transferencias. Entre 1968 y 1970, durante el gobierno dictatorial de Onganía, luego de varias reuniones entre el ministro de educación nacional y los ministros de educación provinciales, se decidió que las transferencias se harían a solicitud de las provincias, cuestión que se instrumentó con la ley $\mathrm{N}^{\circ} 17.878$ que preveía el traspaso de las escuelas de Buenos Aires, La Pampa, La Rioja, Santa Fe, Río Negro y Catamarca. Sin embargo, en esa ocasión, se efectivizaron los traspasos de 680 escuelas repartidas en las provincias de Buenos Aires, La Rioja y La Pampa, al ratificarse sólo 
estos convenios. En 1970 se dictó la ley N 18.596 por la que se pretendía unificar las transferencias de servicios de educación, salud y vialidad, pero no tuvo mayor aplicación salvo en lo referente a la imposibilidad de apertura de nuevas escuelas a cargo de la Nación en territorios provinciales. En 1972, se creó el Consejo Federal de Educación como órgano de coordinación de la conducción educativa y la administración escolar entre nación y provincias (13).

La política de transferencias de Onganía formó parte de un proyecto más amplio de reforma que apuntaba fundamentalmente a modificar la estructura educativa. Para ello, proponía una reducción a cinco años de la escolaridad obligatoria con la denominación de Nivel Elemental y un Nivel Intermedio de tres años entre la educación elemental y la escuela Media. También proponía modificaciones en la carrera de magisterio. En este caso, el criterio se basaba en regular el "exceso" de docentes que egresaba de los normales por medio de la conversión de la formación en nivel terciario (14).

La movilización social (15) y el rol activo de los docentes (16) en rechazo de la reforma, impidieron que ésta pudiese implementarse en su totalidad. Las transferencias mencionadas junto a la transformación de la carrera docente en profesorado, fueron las medidas que se mantuvieron.

Durante el gobierno dictatorial de 1976 a 1983, fue retomado el tema de la transferencia de escuelas primarias a las provincias, en el marco de una transformación mundial del modelo de acumulación. Como veremos en el apartado siguiente, la cuestión de las transferencias constituyó uno de los pilares de la política dictatorial de reestructuración económica y social.

El proceso de transferencias culminó en la década del noventa, cuando se traspasaron a la jurisdicción provincial los niveles medio y terciario no universitario.

\section{La política de transferencias durante la última dictadura argentina}

El gobierno dictatorial, en el marco de una reestructuración económica y social, profundizó la política de descentralización educativa de los gobiernos anteriores. La implementación dictatorial de la política de reestructuración requirió la aplicación simultánea de una política de represión social tendiente a aniquilar a los sectores con capacidad de impugnación pero también con una intencionalidad preventiva y disciplinante hacia el conjunto de la sociedad. Sin embargo, si bien la represión clandestina y paraestatal se había desarrollado en la Argentina como una política de estado desde mediados de la década de 1950 (17) -siguiendo los lineamientos de la Doctrina de Seguridad Nacional-, el bloque social en el poder durante la dictadura produjo 
un salto en la escala y magnitud de la represión (18) dando paso a un plan sistemático que puso los recursos del Estado al servicio de un mecanismo represivo cuya principal característica fue la clandestinidad.

Como planteara Eduardo Luis Duhalde (19), en este contexto, el terrorismo ya no es un instrumento contingente al que se apela para reforzar la coacción que se ejerce públicamente a través del conjunto de órganos represivos estatales sino que pasa a incorporase como una actividad permanente y paralela del Estado mediante una doble faz de actuación- una pública y otra clandestina- de sus aparatos de estado. Se trata, según Duhalde, de institucionalizar con carácter permanente las formas más aberrantes de la actividad represiva ilegal, capaz de sobrevivir en sus elementos constitutivos ilegítimos más allá de la propia vida del régimen que lo implantara (20).

Consideramos que la implementación del terrorismo de estado posibilitó la ejecución de la política de descentralización del nivel primario al debilitar la capacidad de oposición social. No obstante, como veremos más adelante, el proceso no estuvo exento de conflictos y críticas. Así mismo, como planteara Juan Carlos Tedesco (21), las medidas realizadas en política educativa tendieron a la destrucción del sistema educativo imperante.

La transferencia del servicio educativo de nivel primario a las provincias, la Municipalidad de Buenos Aires y al Territorio Nacional de Tierra del Fuego se produjo en dos etapas. La primera, iniciada en mayo de 1976 y sancionada en junio de 1978, consistió en el traspaso de escuelas primarias comunes. La segunda, entre junio de 1978 y diciembre de 1980, efectivizó la trasferencia de escuelas primarias de adultos.

Durante el proceso de transferencia del servicio educativo del nivel primario, tanto el común como el de adultos- hubo cambios de gestión ministerial: Pedro Bruera, Juan José Catalán y Juan Rafael Llerena Amadeo (22). Si bien cada uno de los ministros imprimió un matiz diferencial, las tres gestiones sostuvieron la política de descentralización.

En el discurso de asunción, Pedro Bruera, anunció como objetivos de su gestión, la descentralización educativa y la desburocratización de la administración ministerial. Ambas medidas fueron presentadas, junto a la lucha contra la subversión, como mecanismos para ordenar el sistema educativo.

En abril de 1976, Rafael Videla había anunciado la "necesidad de contener el ritmo creciente de los gastos correspondientes al sector público mediante una política de economía, austeridad y razonabilidad" (23). En respuesta a esa formulación, entre abril y mayo de ese mismo año, el Ministro de Cultura y Educación Pedro Bruera, firmó tres resoluciones que 
autorizaban medidas para recortar gastos en la administración educativa. Dos de ellas se orientaron a "racionalizar" el presupuesto interno de la administración ministerial: reducción del monto de los gastos en el rubro "Homenaje y Cortesía" (24) y limitación de los servicios extraordinarios brindados por el personal administrativo fuera del horario general (25) (horas extras). Esta última medida, según la evaluación del ministro Bruera, se realizaba porque el tema de las horas extras era "uno de los rubros que requiere una inmediata reducción y la sujeción del mismo a estrictas normas de contralor y supervisión" (26). Según el funcionario, la resolución apuntaba a "alcanzar una drástica limitación de los servicios extraordinarios con miras a lograr (...) una real supresión de las mismas" (27). Por ese motivo, se facultó a los jefes de las reparticiones "a controlar estrictamente el cumplimiento efectivo de los servicios extraordinarios, habilitando, de ser posible, la utilización de sistemas mecánicos (relojes de control) y evitando la asignación de cantidades fijas de horas extras a realizar por agentes predeterminados." (28) De este modo, la medida afectó una conquista laboral de los trabajadores de la administración pública vigente desde 1960 (29).

Por otra parte, la tercera medida apuntó a sentar las bases de la política de descentralización educativa en la cual la transferencia del servicio de educación primaria a las jurisdicciones provinciales fue uno de los pilares. El ministro Bruera, el 14 de mayo de 1976, en respuesta a la decisión del Consejo Federal de Educación (CFE) de acelerar el proceso de descentralización de la conducción educativa y la administración escolar (30), resolvió "encomendar a los organismos con dependencia directa del ministerio y a los Consejos Nacionales de Educación y de Educación Técnica, instruyan a sus delegaciones, inspecciones regionales o zonales y funcionarios o supervisores con sede en cualesquiera de las provincias y Territorio Nacional de Tierra del Fuego para que planifiquen y ejecuten, en el nivel de su competencia, las medidas tendientes a dinamizar los procedimientos para acelerar el proceso de una adecuada descentralización (31)". Sin embargo, días antes, el Ministerio de Cultura y Educación, destinó una partida presupuestaria de veinticinco millones de pesos para distribuir entre las provincias (32). Podemos suponer que las provincias que recibieron mayores porcentajes de presupuesto fueron aquellas que presentaban mayores dificultades económicas para sostener el servicio educativo (33). Las provincias que recibieron mayores aportes fueron, en orden decreciente, Tucumán, Santiago del Estero, Misiones, La Rioja, Río Negro, Corrientes y Chaco, seguidas de Formosa, Catamarca, Salta, San Luis y Santa Cruz. 
Por otra parte, el anuncio de la política de descentralización educativa tuvo muy buena recepción en los sectores vinculados con la educación privada. En el mes de junio de 1976, Antonio Salonia declaraba en una nota de opinión que:

"Las actuales autoridades del sector se disponen reanudar un proceso que comenzó en el período 1958-1962 (se aprobó el Estatuto del Docente, se montó el servicio de planeamiento educativo y se estimularon iniciativas técnicos-pedagógicas y administrativas). Es la opinión de quién escribe la de que en este momento existen condiciones singulares e inéditas, expectativas promisorias que integran un programa de gobierno de la educación positivo y auspicioso. La viabilidad de las pautas generales estará condicionada por la maduración del proceso político global, por la consolidación de la estructura del Estado, por la negociación y la expansión del aparato productivo por la eliminación de los factores disociadores y subversivo" (34).

De este modo, en septiembre de 1976 en V Asamblea del Consejo Federal de Educación, realizada en Tucumán, se aprobó la metodología para efectivizar la descentralización progresiva de los servicios educativos de jurisdicción nacional. La misma se realizaría en dos etapas: una de coordinación inmediata y efectiva de acciones entre la jurisdicción nacional y las provinciales y otra de concreción de la medida.

Las negociaciones entre el Estado Nacional y las provincias, gestionadas, en parte, a través de los representantes de cada jurisdicción en el CFE, no estuvieron exentas de conflictos, especialmente si tomamos en cuenta que la medida había sido anunciada para efectivizarse entre fines de 1977 y comienzos del ciclo lectivo de 1978 y terminó por concretarse en junio de ese año.

En los primeros días de marzo de 1977, se produjo un encuentro entre los gobernadores de todas las provincias del país donde se consideró principalmente la cuestión de la transferencia de las escuelas nacionales a la jurisdicción provincial y la relación directa que esta política tenía con la política presupuestaria (35), sin llegarse a un acuerdo.

El 20 de abril renunció Bruera y asumió funciones interinamente el ministro del interior Albano Harguindeguy. Si bien Bruera había avanzado en el desarrollo de los mecanismos para la implementación de las transferencias, éstas no se concretaron hasta mediados de 1978. Al terminar la gestión, la situación laboral docente era crítica. Junto a los docentes desaparecidos y los cientos de cesanteados se sumó el deterioro salarial, la anulación 
parcial de estatuto y otras medidas que afectaban la tarea cotidiana de los maestros. La asunción de Juan José Catalán, en septiembre, no modificó la situación. Por el contrario, el nuevo ministro ratificó la cuestión de las transferencias en le marco de un proyecto educativo de reducción del nivel primario a seis años. Así mismo, Catalán profundizó la política represiva de su antecesor en el ámbito escolar (36).

En el mes de abril, un periódico mencionaba que, en la provincia de Córdoba, "la carencia de maestros en escuelas primarias nacionales y falta de alumnos determina el cierre de escuelas y jardines de infantes". El motivo de la falta de maestros se debía al "alto grado de licencia por parte de los docentes por baja remuneración" (37).

En mayo de 1977, ante el aumento de renuncias de docentes en la provincia de Buenos Aires, La Unión de Educadores de la Matanza publica un artículo denunciando la situación. Según el gremio docente, los motivos de las renuncias masivas se debían a: "el aumento de horas de trabajo sin compensación salarial, al personal administrativo y de psicología, el refundimiento de cursos y grados, la falta de titularización, la no designación en sus cargos a las docentes embarazadas, las numerosas cesantías sin causa justificada y la falta de pago por vacaciones a cesantes y jubilados de oficio" (38).

En el mes de junio, se produjeron renuncias de docentes primarios en las provincias de Santa Fe, Córdoba y Salta (39). Días después, en un artículo publicado en el diario La Prensa, el periodista José María Suares expresaba su desencanto por un aumento en el sueldo de la selección de fútbol y efectuaba una comparación con el sueldo docente, que ubicaba por debajo del sueldo de una empleada doméstica.

Días más tarde, la Confederación de Trabajadores de la República Argentina (CTERA), en un documento titulado "Reflexiones sobre la crisis de la educación" analizaba el tema de la remuneración docente, que había ido en descenso desde 1975 y planteaba que uno de los motivos de las renuncias masivas de dichos profesionales. El documento también comparaba el sueldo de un docente argentino con un docente suizo en similares condiciones de trabajo. El texto finalizaba mencionando la preocupación docente por los continuos cambios en materia de políticas educativas (40).

En septiembre de 1977, en cuatro escuelas primarias de San Martín de los Andes, Neuquén, renunciaron colectivamente a sus cargos treinta y seis docentes "por falta de pago de los sueldos de junio, julio y agosto y del aguinaldo del primer semestre del año", paralizando la actividad escolar (41). 
En el mes de noviembre, la Revista Criterio, publicaba una nota en donde analizaba la crítica situación del sistema educativo. Según el autor de la nota, "los orígenes del deterioro cultural y educativo se remontan a más de una década si bien la diferencia estriba en que el déficit además de ser cuantitativo es cualitativo en los diferentes niveles del sistema. A la deserción escolar se suma la 'deserción magisterial'”. Los motivos enumerados fueron: la baja remuneración, el desprestigio de la actividad docente, la fatiga que genera el trato burocrático, el confuso proceso de los concursos de los cargos docentes y la transferencia a la provincia de las escuelas nacionales (42).

El ciclo lectivo 1977 finalizó con una situación crítica para la docencia. El tema de las transferencias, si bien estaba pautado para finales de ese año, no se concretó.

En los primeros días de 1978, el ministro Catalán anunció un aumento del sueldo docente y la "erradicación de la subversión" (43). El Buenos Aires Herald, en un artículo donde comentaba el tema del aumento salarial a los docentes, formuló una crítica a la política educativa dictatorial, al plantear que "el presupuesto que se ha otorgado a educación en Argentina durante décadas no se condice con la importancia que todos dicen adjudicarle. Argentina solo podrá equipararse a los países que llevan la vanguardia en cultura, política y economía con más presupuesto asignado a educación. El Ministro de Educación, Catalán, asegura que los sueldos docentes aumentarán este año y la educación ocupará un 'estatus prioritario' en el nuevo presupuesto en oposición a lo que hasta hoy ocurría” (44).

En marzo, el Ministro de Cultura y Educación Juan José Catalán, anunció su proyecto de reforma del sistema educativo. La reforma, que se implementaría en seis colegios, consistía en un sistema de seis años de primaria y seis de secundario. Además, propuso la creación de un nivel cuaternario y un sistema de ingreso universitario (45). Respecto a los sueldos docentes, consideraba que la situación se revertiría dado el aumento otorgado en enero y el plan de titularización que pensaba implementar. En el proyecto ratificó la concreción de las transferencias (46), Por otra parte, una directiva de la Subsecretaria de Educación, enfatizaba que "el presente año escolar deberá ser de orden y trabajo (...) la escuela continua siendo la institución educativa por excelencia y de los miembros de la comunidad escolar depende la rehabilitación efectiva de su potencial educador" (47). En otra directiva consecutiva a la anterior, la Subsecretaria fijaba reglas para la elaboración de la doctrina pedagógica y la aplicación de la docencia. Dentro de esta doctrina, que se aplicaría a partir de 1979, "'los maestros y profe- 
sores no intervendrán en la formulación de los objetivos, caracterizaciones y nomina de contenidos porque su función consiste en educar" (48).

La Unión de Maestros Primarios, de Capital Federal, en una carta dirigida a Catalán, cuestionó el plan educativo para el año 1978, afirmando que "omitió diversos y graves problemas como la deserción escolar, la repitencia y el analfabetismo creciente". Esta entidad señalaba la necesidad de un plan inmediato que asegurara el acceso y permanencia en la escuela a todos los niños en edad escolar (49).

Por otra parte, durante el mes de marzo, cerca del plazo estipulado para la efectivización de los traspasos, comenzó con discusiones públicas a favor y en contra del tema (50). En marzo, los funcionarios educativos de las provincias del noreste y del noroeste argentino, aprobaron, en sendas regiones, documentos donde se aprobaba la medida y se establecían las pautas para coordinar las acciones con el estado nacional (51). En el caso de Santiago del Estero, tras un cambio de funcionario al frente de la secretaría de Educación y Cultura de la provincia, se aprobó también el traspaso de las escuelas nacionales (52).

Finalmente, el 9 de junio de 1978 el Poder Ejecutivo Nacional sancionó las leyes de transferencias que hicieron efectivas el 19 de junio, tras la firma de los acuerdos en Santiago del Estero. En la ex legislatura provincial, deliberó la VI Asamblea Extraordinaria del CFE que aprobó unánimemente la "Declaración de Santiago del Estero" donde se estableció el traspaso de los establecimientos educacionales. La Declaración planteaba, en sus puntos centrales, "que las causas que determinaron la creación de escuelas por la nación en jurisdicciones nacionales (ley 4874) han perdido vigencia.; que concebir la educación desde cada provincia significa posibilitar una acción educadora más real y efectiva, al reconocer la variada idiosincracia del hombre argentino, determinada por situaciones geográficas, sociales, económicas y culturales diversas; que la acción educadora se revitalizará por la asistencia inmediata y efectiva de los docentes y su consecuente incidencia en el proceso de enseñanza aprendizaje" (53).

El mismo día de las trasferencias, por la noche, sesionó la VII Asamblea Ordinaria del CFE para fijar las pautas de transferencia de los establecimientos de nivel primario para adultos.

El acto oficial de traspaso se realizó en el Teatro 25 de Mayo, de Santiago del Estero. Asistieron el ministro Catalán, el ministro del Interior Albano Hargindeguy, los gobernadores de veinte provincias, autoridades militares, eclesiásticas y civiles e invitados especiales. En la ceremonia, Catalán expresó en su discurso que: 
"La transferencia de las escuelas primarias nacionales a las provincias tiene una significación política mayor aún que la magnitud de los servicios que se transfieren. Es verdad que 6.500 escuelas nacionales pasan en este momento a ser conducidas y administradas por la provincia pero más verdad aún es que con este acto las provincias dan un importante paso en la afirmación de los derechos que les corresponden por el régimen federal de gobierno" (54).

La transferencia de escuelas primarias comunes se efectivizó a través de la sanción de dos leyes: la Ley Nº 21.809 y la Ley N²1.810. La primera de ellas, facultó al Poder Ejecutivo para transferir, a través de convenios, todas las escuelas, supervisiones y juntas de clasificación dependientes del Consejo Nacional de Educación existentes en jurisdicciones de las provincias, con excepción de las que juzgasen indispensable retener. Tal excepción comprendió, a la Escuela Hogar de Ezeiza, cuatro escuelas diferenciales instaladas en Córdoba, Jujuy y Santa Fe y los Departamentos de Aplicación de las Escuelas Normales.

La ley 21.810, por su parte, asignó a la Municipalidad de la Ciudad de Buenos Aires y la Gobernación de Tierra del Fuego, la competencia en la prestación de la educación pre-primaria y primaria a cargo hasta entonces del Consejo Nacional de Educación, también con algunas excepciones: cuatro escuelas diferenciales, el Instituto Bernasconi (donde funcionaban cuatro escuelas), los Departamentos de Aplicación de las Escuelas Normales y el Hogar Escuela de Capital Federal. También quedaron bajo la órbita nacional el Complejo Cultural de La Boca y la Biblioteca del Maestro (55).

Las escuelas transferidas quedaron bajo la supervisión de los ministerios de educación provinciales y, en el caso de Capital Federal, a cargo de la Secretaría de Cultura y Educación de la Municipalidad de Buenos Aires. El Estado Nacional continuaría liquidando y abonando las remuneraciones del personal que por efecto de la ley quedaba transferido, de los bienes, alquileres y los servicios públicos necesarios para la continuidad de la prestación, por un plazo máximo de nueve meses a partir del 1 de enero de 1978. El Ministerio de Educación y Cultura de la Nación, no obstante, seguiría fijando la política educacional, los planes de estudio y el control de su ejecución. El diseño de los programas de estudio y de los contenidos básicos quedó a cargo del Consejo Federal de Educación (56). De este modo, desapareció el Consejo Nacional de Educación después de haber guiado la educación primaria de casi todo el país durante aproximadamente un siglo. 
La diferencia de las transferencias de 1978 con las anteriores es que en las primeras leyes, la transferencia era gradual y optativa. Con la legislación de 1978, la transferencia fue obligatoria.

El proceso de transferencias generó el cierre de establecimientos con la consiguiente pérdida de puestos de trabajo docentes y la superpoblación de escuelas. A su vez, como veremos en el apartado siguiente, cuando analicemos el caso porteño, hubo manifestaciones públicas de diversos actores sociales en contra de las transferencias y sus resultados inmediatos.

Por otra parte, el mismo proceso favoreció el crecimiento del sector privado. Según el ministro de Hacienda Juan Aleman, era necesario "invertir donde rinde más lo que se invierte", pues, "debido al cobro de aranceles, el costo por alumno es más bajo para el Estado en la enseñanza privada; por lo tanto, ésta es más barata que la pública" (57). A tono con esa premisa, en 1979, el ministro Juan Rafael Llerena Amadeo, en la XXXVII Reunión de la Conferencia Internacional de Educación de la UNESCO, anunciaba en su discurso que:

“(...) El incremento del presupuesto nacional para el sector educación en los últimos años, se ha favorecido en el presente por las medidas de descentralización operativa de la Educación Primaria (...)" (58).

Así como Llerena Amadeo justificaba el beneficio económico para el presupuesto educativo que habían significado las transferencias, también resaltaba la importancia que el gobierno otorgaba a la educación privada. En el mismo mensaje, el ministro argumentaba que:

"Junto con la educación pública estatal, y coordinada sin prevalecencias, tiene un rol destacado la acción que desarrolla la educación pública privada, que canaliza la iniciativa de los particulares y evidencia la plena vigencia de la libertad de enseñar y aprender en nuestro país. Este aporte se extiende no sólo al nivel primario y medio sino también alcanza el nivel terciario no universitario y la universidad" (59).

En diciembre de 1980, se sancionaron y promulgaron dos leyes para la transferencia de escuelas primarias de adultos. La ley 22.367 (60) por la cual se traspasaba la prestación de la educación de nivel primario de adultos (escuelas, supervisiones y juntas de clasificación) a las provincias y la Ley 22.369 que establecía lo mismo para la Municipalidad de la Ciudad de Buenos Aires y el Territorio Nacional de Tierra del Fuego, Antártida e Islas del Atlántico Sur. En ambos casos hubo excepciones. Por ejemplo, en 
Capital Federal quedaron excluidos los establecimientos de nivel primario anexos a unidades de las Fuerzas Armadas y su supervisión, la Junta de Clasificación Zona I (DINEA), la escuela experimental Manuel Belgrano y las dos escuelas del Instituto Bernasconi, entre otras. En el apartado siguiente analizaremos el caso de Capital Federal.

\section{La Municipalidad de Buenos Aires y la política de transferencia}

La elección del caso de la Municipalidad de Buenos Aires responde a las particularidades que presentaba esta jurisdicción -Capital Federal de la Nación- que la diferenciaba de los casos provinciales.

Por una parte, mientras en el ámbito provincial, el poder ejecutivo estaba a cargo de un gobernador elegido por medio del sufragio, la autoridad municipal -los intendentes- se elegía desde el Poder Ejecutivo Nacional. Durante el período dictatorial, la Intendencia de la Municipalidad de Buenos Aires estuvo a cargo, sucesivamente, del General de Brigada (R) Eduardo Crespi (61) (entre el 24 de marzo y el 2 de abril de 1976), el Brigadier (R) Osvaldo Cacciatore (abril de 1976 al 31 de marzo de 1982) y Guillermo Del Cioppo (marzo de 1982 a diciembre de 1983). El proceso de transferencias se realizó durante la intendencia del Brigadier Cacciatore.

Por otra parte, la situación de Capital de Estado de la jurisdicción, otorgaba a la región metropolitana un estatuto diferenciado con el resto del país (excepto con el Territorio Nacional que tenía la misma particularidad) en relación a la administración escolar. La totalidad de los establecimientos educativos porteños, con pocas excepciones (62), pertenecían a la órbita nacional y estaban administrados por el Consejo Nacional de Educación.

Como ya señalamos, la ley 21.810 (63) asignó a la Municipalidad de la Ciudad de Buenos Aires la competencia, con algunas excepciones, en la prestación de la educación pre-primaria y primaria a cargo, hasta entonces, del Consejo Nacional de Educación. Se traspasaron aproximadamente 430 escuelas de primaria común (64) y diecinueve (65) quedaron en la órbita nacional. En 1980 se transfirieron 140 establecimientos educativos del nivel primario de adultos.

La municipalización de escuelas generó la creación de la Secretaría de Cultura y Educación de la Municipalidad de Buenos Aires como organismo administrativo. Desde su creación hasta la finalización de la dictadura, estuvo a cargo de la misma el vicecomodoro (R) Enrique José Sanzo (66).

Docentes que entrevistamos señalan que el tema de las transferencias generó posiciones encontradas dentro de la docencia, a favor y en contra, que derivaron, con el paso del tiempo y por razones divergentes, en un sentimiento de disconformidad. Para algunos, la municipalización 
provocó ciertas expectativas iniciales ligadas a percepciones de mejoras administrativas pero luego, la percepción de caos y desorden posterior a los traspasos, generaron disconformidad (67). Para otros, en cambio, el tema de los traspasos fue motivo de resquemor, e incluso de rechazo, desde un comienzo (68). En estos casos existían temores previos ya sea por una disminución salarial, sea por temor a la pérdida de cargos.

Si bien el cuerpo de la Ley de Transferencias establecía una garantía a la estabilidad docente, el proceso da traspasos implicó el cierre de escuelas y la reestructuración administrativa.

La resolución del 23 de noviembre de 1978 dejó sin trabajo a varios docentes invocando la necesidad de tomar medidas sobre "Racionalización de personal por razones de servicio" (69). El gremio porteño Unión de Maestros Primarios (UMP), elevó una carta a la Municipalidad de Buenos Aires el 26 de diciembre de 1978 reclamando sobre estos hechos. En la nota se planteaba que:

"Esto ha causado estupor y profunda inquietud en la docencia puesto que se aseguró y se reiteró que el traspaso no afectaría la estabilidad de los educadores (...). En las consideraciones de la Ley 21.810 y en su Decreto Reglamentario $N^{\circ} 1.230$ (...) se señala que: se han previsto todos los recaudos para que el servicio educativo se siga cumpliendo normalmente y para que el personal docente no se vea perjudicado en ningún caso, en sus intereses de remuneración, estabilidad y regímenes provisionales o asistenciales" (70).

La UMP había sido bastante crítica respecto a las trasferencias y a la política educativa del ministro Juan José Catalán.

La cuestión de la deserción escolar denunciado por UTE en 1978 se agravó en los siguientes años, particularmente en las escuelas primarias municipales. Posiblemente, la superpoblación en algunas escuelas (71), producto del cierre de instituciones junto al Decreto sancionado en noviembre de 1979, por el cual se determinó las prioridades en lo referido a la inscripción de alumnos en las escuelas municipales "a aquellos que vivan en la Capital Federal, dentro de un radio menor a diez cuadras del centro educativo en el que se inscriben" (72).

El tema de la deserción escolar se convirtió en política municipal en 1981 cuando la Secretaría de Educación de la MCBA lanzó un "Programa de retención escolar" orientado a los Supervisores. El documento incluía una serie de medidas a tomar con el objetivo de erradicar la deserción escolar del nivel primario y especial en el ámbito de la Capital Federal en los 
servicios de responsabilidad municipal. En realidad, la propuesta consistió en la organización de seminarios en las instituciones educativas donde "cada escuela pueda evaluar su eficiencia interna y delimitar los factores que comprometen el desempeño escolar. Las conclusiones a las que arribe cada institución servirán para a programación de actividades del año 1982 y sucesivos. Además se busca la elaboración de estrategias de mediano plazo para enfrentar esta problemática" (73).

Por otra parte, la municipalización implicó la formulación de normativa acorde con la regionalización.

El 8 de febrero de 1979, la Secretaría de educación de la Municipalidad de Buenos Aires aprobó un plan y programa de estudios (74) para la Capital Federal. Ese mismo año, la Secretaría de Educación de la MCBA lanzó un proyecto de capacitación docente a realizarse en dos etapas: la primera, ese año y la segunda, en 1980. El proyecto se llamó Programa de Capacitación y apoyo al docente (PROCAD). Según Haydée, una docente entrevistada, los módulos del programa se entregaban en las escuelas. Los docentes debías estudiarlo y luego, a fin de año, les tomaban un examen para evaluar si habían aprendido el contenido de los cuadernillos (75).

En una editorial del 30 de marzo de 1980, Máximo Gainza, director del diario La Prensa, señalaba que "distintos hechos comienzan a señalar que los docentes que se desempeñan en el nivel jurisdiccional municipal han perdido su derecho a manifestar sus opiniones sobre asuntos de su interés y competencia. Esto no se puede aceptar, no se puede negar al maestro que opine sobre temas educativos cuando se le ha encomendado la misión de educar e instruir" (76).

El 28 de noviembre de 1980, la Secretaría de Educación de la MCBA resolvió aprobar un Diseño curricular para la MCBA que se puso en vigencia en marzo de 1981. El motivo por el cual se aprobó ese Diseño Curricular fue "que las escuelas transferidas al ámbito de la MCBA (...) no cuentan con planes y programas de estudio para su aplicación uniforme (pues) en la actualidad tienen aplicación indistinta los aprobados en los años 1973 y 1976 por el CNE y el aprobado por la Secretaría de Educación en el año 77" (77). Este Diseño se basó en los contenidos mínimos fijados por el Consejo Federal de Cultura y Educación (78) en la IV Asamblea Extraordinaria de dicho organismo realizada en La Plata entre el 16 y 17 de diciembre de 1976 y aprobados por el Ministerio de Cultura y Educación de la Nación el 17 de febrero de 1977, durante la gestión de Bruera (79). En el Diseño, se incluyeron propuestas de actividades para realizar e indicaciones para enseñar los objetivos y contenidos destinadas a los docentes, limitando su 
autonomía en la toma de decisiones no sólo en relación a qué enseñar sino también en relación a cómo hacerlo.

En mayo de 1981, el Partido Comunista Argentino, en un folleto titulado "Primeras reflexiones sobre el nuevo Programa de estudios de las Escuelas Primarias Municipales" señalaba la "falta de participación y consulta a los docentes en la confección de este nuevo diseño curricular" así como manifestaba "dudas sobre la posible mejora en la calidad de la educación, pues el éxito del aprendizaje no depende solamente de la calidad de maestros y programas sino de una asistencia integral al alumno para eliminar las causas socio-económicas que determinan el fracaso Escolar y la deserción". EI PCA proponía la realización en los distintos Distritos Escolares de "instancias de participación, de reflexión y debate, donde puedan expresar sus opiniones todos los sectores implicados: docentes, padres, cooperadores, especialistas y las instituciones vinculadas a la educación" (80).

La situación docente no sólo estuvo afectada por el cierre de cargos (81) y la redefinición de su tarea -limitada a enseñar los contenidos y aplicar los objetivos y actividades que "expertos" habían definido en el Diseño- o la capacitación compulsiva sino que también, la municipalización implicó la sanción de un estatuto.

El 25 de septiembre de 1979 se había sancionado el Estatuto del Docente Municipal (82), poniéndose en vigencia a partir del 1 de octubre de ese año. En la parte correspondiente a "Deberes" del docente se introdujo la cosmovisión del PRN pues se establecía que el personal docente estaba obligado a "sustentar los principios democráticos y republicanos que establece la Constitución Nacional y formar en los alumnos una conciencia y respeto a esos principios y a los valores de la moral cristiana" (83).

\section{A modo de conclusión}

Como señalamos en la introducción, la aplicación de políticas neoliberales tendientes a la reducción del gasto público, la descentralización administrativa y la privatización de servicios sociales, produjo durante la última dictadura argentina una paulatina transformación del rol del estado con consecuencias tanto para los sectores sociales más pobres como para los trabajadores estatales. En este marco, los ejecutores del autodenominado "Proceso de Reorganización Nacional" (PRN) profundizaron la tendencia de las décadas anteriores de modernización del sistema educativo, subordinándolo a las demandas del mercado y al modelo de distribución regresiva de la renta mediante el estímulo a la educación privada pero también con intenciones de arancelar la enseñanza estatal no obligatoria. La propuesta educativa global del bloque social en el poder descargó en las economías 
regionales la atención de la demanda educativa, agravando problemas estructurales que ya presentaba el sistema como el acceso desigual a la educación, la deserción escolar, el bajo sueldo docente o el deterioro de las instalaciones educativas.

Uno de los pilares de la política educativa dictatorial fue retomar la tendencia a la descentralización de la educación y la administración escolar que se venía ensayando en el país desde finales de la década del cincuenta. A diferencia de las experiencias anteriores, donde la movilización social logró revertir, en parte, las medidas implementadas, durante la dictadura, la utilización del terror de Estado como método permanente, limitó la capacidad de oposición social. No obstante, como señalamos con anterioridad, el proceso de transferencias no estuvo exento de conflictos. Uno de ellos, tal vez como forma pasiva de oposición, fue la renuncia masiva de docentes. Otro, las acciones de denuncia generadas por gremios docentes y algunos partidos y medios de comunicación. Finalmente, los cambios de gestión en la cartera educativa nacional que, si bien coincidieron en la concreción de medidas tendientes a la descentralización y la transferencia de servicio educativo hacia las jurisdicciones provinciales y la municipal, muestran un entramado político no exento de conflictividad.

Por otra parte, la política del PRN de transferencias no estuvo acompañada de medidas relacionadas con los problemas de deserción escolar o con el deterioro de las condiciones laborales docentes. Por el contrario, el traspaso del nivel primario a las provincias, al descargar en los presupuestos provinciales el servicio educativo, agravó la situación y posibilitó el crecimiento de las ofertas educativas privadas.

Así mismo, en este artículo centramos la atención en el devenir de la situación laboral docente a lo largo del proceso estudiado. Mostramos cómo los bajos salarios junto a la represión, significaron un descenso de docentes que se agravó con el cierre de puestos de trabajo después de efectivizadas las transferencias. A esta situación se sumó, por lo menos en el caso de la Municipalidad de Buenos Aires, una serie de medidas que limitaron la autonomía docente en relación al proceso de enseñanza-aprendizaje.

En síntesis, las transferencias no fueron articuladas con medidas que acompañaran a las regiones en la resolución de problemas como la deserción escolar y el deterioro de las condiciones laborales docentes. Por el contrario, los resultados fuero el cierre de escuelas, la superpoblación de aulas, la pérdida de puestos de trabajo y la renuncia masiva de docentes.

Esperamos que futuras investigaciones continúen profundizando en las cuestiones que dejamos planteadas en este trabajo. 


\section{Notas Bibliográficas}

(1) Para ello, los funcionarios educativos del régimen partieron de un diagnóstico donde la escuela pública fue evaluada como "deteriorada", "desjerarquizada", "inadecuada al desarrollo económico del país", culpando al estado de no haber ejercido "oportunamente su responsabilidad de mantenerla a la altura de los tiempos". Por ese motivo, se propuso "mantener la gratuidad de la enseñanza obligatoria, tendiendo al arancelamiento en los niveles no obligatorios". Este diagnóstico y la propuesta mencionada se encuentran en la introducción del Programa de Política educativa de 1978. Ver Ministerio de Cultura y Educación, Programa de Política Educativa, Buenos Aires, 1978. Este tema también ha sido abordado por Pablo Pineau. Ver, Pineau, P. y otros (2006), El principio del fin. Políticas y memorias de la educación en la última dictadura militar (1976-1983), Buenos Aires, Colihue, p. 75 y p.106. Sobre el tema de la contextualización de estas medidas en un proceso más amplio, ver nuestro artículo Gudelevicius, M. (2008) "Argentina, 1976-1983: historias de solidaridad, oposición y resistencia a la dictadura en el ámbito escolar" en Historia, voces y memoria. Boletín del Programa de Historia oral de la facultad de Filosofía y letras de la UBA, Buenos Aires, El colectivo, vol. 2, primer semestre, p. 75. Para el tema de la repercusión de estas medidas en los sectores populares, ver Tedesco, J. C. (1983) El proyecto educativo autoritario, Buenos Aires, FLACSO.

(2) Constitución Nacional, Art.67 Inc.16.

(3) En una investigación anterior, hemos comprobado que uno de los motivos que obstaculizaron el logro de la unidad sindical docente fue la existencia de este doble circuito de escuelas. Ver Gudelevicius, M. (2007) "Las luchas por la sanción del Estatuto del Docente en Argentina y sus implicaciones para los trabajadores de la educación primaria", I Jornadas de trabajos, investigaciones y experiencias de los graduados de historia de la UBA, 9 de noviembre, p. 2.

(4) Según las percepciones de docentes que entrevistamos, el sentido común de la sociedad adjudicaba mayor calidad educativa a las escuelas primarias nacionales. En este sentido, para un docente, resultaba más prestigioso trabajar en una escuela primaria nacional que en una provincial. Además, en términos salariales, también señalan diferencias considerables. Un paradigma de escuelas nacionales fueron las escuelas Normales, que no sólo se ocupaban de la formación de docentes sino que, además, establecían una articulación entre el magisterio y los Departamentos de Aplicación. Otro ejemplo paradigmático fue el Instituto Félix Bernasconi, de Capital Federal.

(5) Ver Gudelevicius, M. (2007) "Las luchas por la sanción del Estatuto del Docente en Argentina y sus implicaciones para los trabajadores de la educación", I Jornadas de trabajos, investigaciones y experiencias de los graduados de historia de la UBA, 9 de noviembre, p. 10.

(6) Recomendaciones de la CEPAL. Boletín del Proyecto Principal de Educación № 10, abril-junio 1961.

(7) Desde 1955, por iniciativa del gobierno militar, había comenzado una fuerte campaña por la promoción de la enseñanza libre en el ámbito universitario y 
superior. El Decreto 6403 avalaba esta tendencia. El gobierno de Arturo Frondizi en agosto de 1958, siguiendo esta línea, lanzó la iniciativa para una apertura generalizada de centros de enseñanza fuera del ámbito estatal al reglamentar el artículo 28 del mencionado Decreto.

(8) Ley de Presupuesto $N^{\circ} 15.796$ del ejercicio 61/62.

(9) Decreto $N^{\circ} 495 / 62$.

(10) Entrevista a Ángel Turconi, 2007, Archivo de UTE.

(11) Paro nacional de cinco días convocado por la Unión de Maestros Primarios en el Comité Unificador Docente de Acción Gremial (CUDAG) el 19 de agosto de 1963. El CUDAG estaba conformado mayoritariamente por docentes de Capital Federal.

(12) Paro de 48 hs. del 5 de julio de 1963. Convocó el CUDAG pero el CUDEBA no apoyó. EI CUDEBA nucleaba a docentes bonaerenses.

(13) Ley 19.682.

(14) De Luca, R. (2008), "Formación docente y reformas educativas en la Argentina entre los años sesenta y noventa", VII Seminario de la Red ESTRADO, Buenos Aires, 3, 4 y 5 de julio, p. 1.

(15) A partir de 1969, cristalizada en el "Cordobazo", crece la radicalización social.

(16) Entre 1968 y 1972 hubo una fuerte movilización docente en rechazo al proyecto educativo de Onganía. Uno de los ejemplos más notables fue en Mendoza, en 1971, conocido como "Mendozazo".

(17) Duhalde, E. L. (1999) El Estado Terrorista Argentino. Quince años después, una mirada crítica., Buenos Aires, Eudeba, p. 32.

(18) Novaro, M. y Palermo, V. (2003) Historia Argentina. La Dictadura militar 1976/1983. Del golpe de estado a la restauración democrática, Buenos Aires, Paidós, Tomo 9, p. 20. Duhalde, E. L. (1999) El Estado Terrorista Argentino. Quince años después, una mirada crítica. Buenos Aires, Eudeba.

(19) Duhalde, E. L. (1999) El Estado Terrorista Argentino. Quince años después, una mirada crítica. Buenos Aires, Eudeba., pp. 217-236.

(20) En este sentido, compartimos análisis como los de Daniel Feierstein que interpretan estas acciones como prácticas genocidas cuyo objetivo es, en última instancia, transformar a la sociedad toda con efectos que perduran más allá del contexto histórico en el que se ejecuta. Ver Daniel Feierstein, El genocidio como práctica social. Entre el nazismo y la experiencia argentina; Buenos Aires, FCE, 2007.

(21) Tedesco, J. C. (1983) El proyecto educativo autoritario. Buenos Aires, FLACSO.

(22) Si bien durante los días posteriores al golpe de estado, ocupó la cartera educativa el delegado militar César Guzzetti, formalmente, Pedro Bruera, fue el primer ministro de Cultura y Educación del PRN. Estuvo en el cargo desde abril de 1976 hasta que su enfrentamiento con Eduardo Constantini, rector de la UBA terminó con su renuncia el 20 de abril de 1977. Luego de un período en 
que estuvo a cargo interinamente el Ministro del Interior, Albano Hardindeguy, asumió funciones en la cartera educativa Juan José Catalán, a mediados de 1977. Este último, también por un enfrentamiento con el rector de la UBA, en este caso, Luis Cabral y por las fuertes críticas a su gestión, renunció en agosto de 1978. Hargundeguy volvió a ocupar interinamente el cargo hasta la asunción de Juan Rafael Llerena Amadeo, en noviembre de 1978. En marzo de 1981 fue reemplazado por Carlos Burundarena.

(23) Clarín, "El presidente anuncia medidas", 4 de abril de 1976.

(24) Ministerio de Cultura y Educación de la Nación, Resolución N ${ }^{\circ} 37$ del 26/4/76.

(25) Ministerio de Cultura y Educación de la Nación, Resolución № 24 del 20 de abril de 1976.

(26) Idem.

(27) Idem.

(28) Idem.

(29) Decreto 10.357/60.

(30) En Buenos Aires, el 10 de mayo de 1976, se produjo la III Reunión Extraordinaria del CFE. En esa reunión se acordó intensificar una coordinación efectiva entre Nación y Provincias, a fin de posibilitar la descentralización educativa.

(31) Ministerio de Cultura y Educación de la Nación, Resolución № 119, punto b), del $14 / 5 / 76$.

(32) Aportes del Estado en el marco del "Operativo P.A.I.S" vigente desde el año 1971. La información fue extraída de Ministerio de Cultura y Educación de la Nación, Resolución $N^{\circ} 84,6 / 5 / 76$. En esa oportunidad de designaron $\$ 25.000 .000$ para la aplicación del Operativo.

(33) Nos estamos manejando en el plano hipotético pues la asignación de un porcentaje presupuestario mayor también se puede deber a la existencia en esas jurisdicciones de un mayor número de establecimientos nacionales, cuestión que complejiza pero no invalida el supuesto de anticipación de sentido mencionado.

(34) Salonia, A. ¿En la antesala del gran cambio educativo?, EI PAIS, S.A, julio de 1976, p. 81 y 83.

(35) Clarín, "Tratarán el traspaso de escuelas a las provincias", 5 de marzo de 1977, p. 9.

(36) A partir de una evaluación del ámbito educativo como espacio favorable para el desarrollo de la subversión, el Ministro Catalán implementó, a través de las autoridades educativas, una campaña de información sobre cómo detectar elementos subversivos y los procedimientos a seguir para erradicarlos. Ver MCE, Res № $538 / 77$ y la RES № 44/77 de la Secretaría de Estado de Educación.

(37) Clarín, "Córdoba: falta de alumnos", 14 de Abril de 1977, p. 14.

(38) El artículo aparece en el periódico Elementos, relacionado con el PC. Registro de la propiedad intelectual en trámite - Impreso en Alemann y Cia., 25 de Mayo 626. Autor, Mario Alderete. 
(39) El artículo aparece en el periódico Elementos, relacionado con el PC. Ver Mario Alderete, "Continúa la fuga de maestros"; en Elementos, Buenos Aires, 1 de junio de 1977.

(40) El documento aparece en Mario Alderete, "Nueve carillas para reflexionar", en Elementos, Buenos Aires, 29 de junio de 1977.

(41) "Pago a docentes con mucha demora", Clarín, 13 de septiembre de 1977. Las escuelas afectadas fueron la 89, la 102, la 5 y la 134, donde concurrían un total de ochocientos alumnos. En el resto de la provincia de Neuquén, según el diario consultado, se habían producido demoras salariales similares pero sin la renuncia del personal.

(42) "El Deterioro Educativo", Revista Criterio, Buenos Aires, 10 de Noviembre de 1977 , p. 603 y 606.

(43) Buenos Aires Herald, ¿Un futuro para la docencia?, 5 de enero de 1978.

(44) Buenos Aires Herald, ¿Un futuro para la docencia?, 5 de enero de 1978.

(45) Diario Clarín, "Catalán anunció las reformas que se llevarán adelante en el sistema educativo", 21 de marzo de 1978, p. 18.

(46) Revista Somos, Ministro Catalán: ¿Esta educación merecen los argentinos?, 10 de marzo de 1978, pp. 8-13.

(47) La Nación, "Prepáranse nuevas normas pedagógicas oficiales", 13 de marzo de 1978, p.10.

(48) La Nación, "Preparanse nuevas normas pedagógicas oficiales", 13 de marzo de 1978, p.10.

(49) Diario Clarín, "proponen a Catalán un plan inmediato", 28 de marzo de 1978, p. 24.

(50) Clarín, "transferencia: la Ley demorada", 2 de febrero de 1978, p. 11.

(51) Ver Diario Clarín, "todo listo para recibir las escuelas nacionales", 9 de marzo de 1978, p.1 y Diario Clarín, "El NOA educativo y la transferencia de escuelas", 13 de marzo de 1978, p. 30.

(52) Diario Clarín, "todo listo para recibir las escuelas nacionales", 9 de marzo de 1978, p.1.

(53) El litoral, "A las provincias se traspasaron escuelas", 19 de julio de 1978, p. 1 y 4.

(54) El litoral, "A las provincias se traspasaron escuelas", 19 de julio de 1978, p. 1 y 4.

(55) Decreto $N^{\circ} 1231 / 78$.

(56) Decreto № 1231/78.

(57) Tedesco, J. C.; Braslavsky, C. y Carciofi, R. (1985), El proyecto educativo autoritario (1976-1983). Buenos Aires, Gel, p. 91.

(58) "Educar para la Paz .Texto del Mensaje del Ministro de Cultura y Educación DR. Juan Rafael Llerena Amadeo, en la XXXVII Reunión de la Conferencia Internacional de Educación de la UNESCO, pronunciado en el Palais Wilson, en Ginebra (Suiza) el 6 de julio de 1979" en Ministerio de Cultura y Educación. Buenos Aires, 1979. 
(59) Idem.

(60) Boletín Oficial, Ley 22.367 sancionada y promulgada el 31/12/80 y publicada el $19 / 1 / 81$.

(61) Dejó el cargo para formar parte de la CAL.

(62) Según las estadísticas del año 1974, en el área porteña existían 1.169 establecimientos educativos de nivel primario (entre públicos y privados) de los cuales, 888, aproximadamente, pertenecían al nivel primario común. Entre estos, 9 pertenecían a la administración municipal y 507 a la nacional. Ver Departamento de Estadística del MCE, Estadísticas de la Educación, Buenos Aires, 1974.

(63) Ley $N^{\circ} 21.810 / 78$ reglamentada por el Decreto $N^{\circ} 1.230 / 78$.

(64) El número puede ser menor pues extrajimos los datos de una estadística del año 81. Ver, Departamento de Estadística del MCE, Estadísticas de la Educación, Buenos Aires, 1981.

(65) 14 Departamentos de Aplicación, las 4 escuelas pertenecientes al Instituto Bernasconi y la Escuela Hogar. Ver Decreto No 1.230/78.

(66) La única referencia que hemos encontrado en relación a la trayectoria previa de Sanzo es que fue miembro de la tripulación que realizó el primer vuelo a la Base Marambio, en la Antártida, el 29 de octubre de 1969, día en que fue creada.

(67) Entrevista realizada por Mariana Gudelevicius a Horacio el 20 de mayo de 2009 en la Ciudad de Buenos Aires.

(68) Entrevista a Haydée, abril de 2009, realizada por Mariana Gudelevicius.

(69) Municipalidad de Buenos Aires, Resolución № 7758/78, 23 de noviembre de 1978.

(70) Nota de la UMP al intendente de la Municipalidad de Buenos Aires, brigadier (RE) Osvaldo Andrés Cacciatore del 26 de diciembre de 1978. Archivo UTE.

(71) Diario La Prensa, Marta Cao, "orientación y reeducación para el 'niño problema' en las escuelas primarias", 4 de abril de 1979, p. 1.

(72) Boletín Municipal N 16148Decreto $N^{\circ} 6325$ / 979. Inscripción de alumnos en Escuelas Municipales 9 de noviembre de 1979.

(73) MCBA, Secretaría de Educación, Programa de retención escolar, Buenos Aires, 1981.

(74) MCBA, Secretaría de Educación, "organización Curricular", Buenos Aires, 1979.

(75) Entrevista a Haydée, abril de 2009, realizada por Mariana Gudelevicius.

(76) La Prensa, "Los maestros y el derecho a opinar", nota editorial, Máximo Gainza, 30 de marzo de 1980.

(77) Secretaría de Educación de la MCBA, RES. № 3.000.

(78) El Consejo Federal de Cultura y Educación se creó en 1980 por medio de la Ley $\mathrm{N}^{\circ} 22047$, reemplazando al Consejo Federal de Educación y al Consejo Federal de Cultura.

(79) MCE, CFE, "Objetivos pedagógicos del nivel primario y contenidos mínimos del nivel primario común”, Buenos Aires, 1977. 
(80) PCA, "Primeras reflexiones sobre el nuevo Programa de estudios de las Escuelas Primarias Municipales", CE.D.IN.C.I., Catálogo $N^{\circ} 1$, Partido Comunista Argentino. Folleto.

(81) No hemos encontrado cifras para establecer la cantidad de escuelas cerradas y los cargos afectados en nivel primario común. Nos manejamos con la información obtenida por medio de testimonios de docentes. En el caso de educación primaria de adultos, hemos encontrado algunas cifras. El 14 de marzo de 1981, el periódico Buenos Aires Herald, denunciaba que "el trabajo de 600 profesores se verá en peligro debido al desacuerdo entre el Ministerio de Cultura y Educación y la Municipalidad de Buenos Aires sobre la transferencia de los programas especiales (...). La Municipalidad había convenido aceptar 140 escuelas en las cuales los adultos reciben instrucción primaria, pero se rehúsan a encargarse de los programas especiales adjuntos". Ver Buenos Aires Herald, "La municipalidad rechaza programas educativo" / Municipality rejects education programs, 14 de marzo de 1981.

(82) Boletín Municipal, Ordenanza 35.234/79, Estatuto del Docente Municipal.

(83) Boletín Municipal, Ordenanza № 35.234, Estatuto del Docente Municipal, art.6, inc b., Buenos Aires, 1/10/ 79.

\section{Referencias Bibliográficas}

- Duhalde, E. L. (1999) El Estado Terrorista Argentino. Quince años después, una mirada crítica. Buenos Aires, Eudeba.

- Gudelevicius, M. (2007) "Las luchas por la sanción del Estatuto del Docente en Argentina y sus implicaciones para los trabajadores de la educación”, I Jornadas de trabajos, investigaciones y experiencias de los graduados de historia de la UBA, 9 de noviembre.

- Gudelevicius, M. (2008) "Argentina, 1976-1983: historias de solidaridad, oposición y resistencia a la dictadura en el ámbito escolar" en Historia, voces y memoria. Boletín del Programa de Historia oral de la facultad de Filosofía y letras de la UBA, Buenos Aires, El colectivo, vol. 2, primer semestre.

- Novaro, M. y Palermo, V. (2003) Historia Argentina. La Dictadura militar 1976/1983. Del golpe de estado a la restauración democrática. Buenos Aires, Paidós, Tomo 9.

- Pineau, P. y otros (2006) El principio del fin. Políticas y memorias de la educación en la última dictadura militar (1976-1983). Buenos Aires, Colihue.

- Tedesco, J. C. (1983), El proyecto educativo autoritario. Buenos Aires, FLACSO.

- Tedesco, J. C.; Braslavsky, C. y Carciofi, R. (1985) El proyecto educativo autoritario (1976-1983). Buenos Aires, Gel. 